\title{
General Psychiatry Study on risk factors of extrapyramidal symptoms induced by antipsychotics and its correlation with symptoms of schizophrenia
}

\author{
Jiajun Weng, ${ }^{1,2}$ Yan Zhang, ${ }^{1,2}$ Huafang Li, ${ }^{1,2}$ Yifeng Shen, ${ }^{1,2}$ Wenjuan Yu ${ }^{1,2}$
}

To cite: Weng J, Zhang Y, Li H, et al. Study on risk factors of extrapyramidal symptoms induced by antipsychotics and its correlation with symptoms of schizophrenia. General Psychiatry 2019;32:e100026. doi:10.1136/ gpsych-2018-100026

Received 28 October 2018 Revised 10 January 2019 Accepted 14 January 2019

\section{Check for updates}

(c) Author(s) (or their employer(s)) 2019. Re-use permitted under CC BY-NC. No commercial re-use. See rights and permissions. Published by BMJ.

${ }^{1}$ Drug Clinical Trial Institution, Shanghai Mental Health Center, Shanghai, China

${ }^{2}$ Psychiatry, Shanghai Mental Health Center, Shanghai, China

Correspondence to

Wenjuan Yu;

wenjuanyu2004@163.com

\section{ABSTRACT}

Background Extrapyramidal symptoms (EPS) are one of the most common and neglected side effects during the treatment of schizophrenia. The risk factors of EPS in Chinese patients with schizophrenia and its relationship with psychiatric symptoms and mood symptoms of schizophrenia remain unknown.

Aims The main objective of this study is to explore the risk factors of EPS caused by antipsychotics and the relationship between EPS and psychotic symptoms and mood symptoms of schizophrenia.

Method This study included 679 patients with schizophrenia who have met the diagnostic criteria of the Diagnostic and Statistical Manual of Mental DisordersFourth Edition. Patients were divided into the EPS group and the non-EPS group according to the scale rating criteria and whether the anticholinergics have been used. The differences between demographic data and characters of drug intake were compared between the two groups, and the risk factors of EPS were selected between those factors. Correlation analysis was performed on the severity of schizophrenia (Positive and Negative Symptoms Scale (PANSS), Calgary Depression Scale for Schizophrenia (CDSS) score) and EPS scale (Simpson-Angus Scale (SAS), Barnes Akathisia Rating Scale (BARS), Abnormal Involuntary Movement Scale (AIMS) score) in 679 patients. The differences between the PANSS subscale score and the CDSS score between the EPS group and the non-EPS group were compared.

Result Compared with the non-EPS group, the EPS group patients are older, and they have a longer duration since first prescribed antipsychotics. The EPS group patients have higher frequency of atypical antipsychotics polytherapy and typical and atypical antipsychotics polytherapy or combined treatments with mood stabilisers. Logistic regression analysis shows that antipsychotics with high D2 receptor antagonistic effect and illness duration are the risk factors of EPS. The SAS score was significantly correlated with PANSS negative score, PANSS general psychopathological score and PANSS total score. The BARS scale score was significantly correlated with PANSS positive score, PANSS general psychopathological score, PANSS total score and CDSS total score. The AIMS scale score was significantly correlated with PANSS negative score. Compared with the non-EPS group, the EPS group patients have significantly higher PANSS negative score, PANSS general psychopathological score, PANSS total score and CDSS total score.
Conclusion Antipsychotic drugs with high D2 receptor antagonism and disease duration are risk factors of EPS in Chinese patients with schizophrenia. The severity of various types of EPS is significantly correlated with the psychiatric and mood symptoms of schizophrenia, and psychiatric symptoms and mood symptoms were significantly more severe in the EPS group. The occurrence of EPS is associated with poor treatment outcome of schizophrenia.

\section{INTRODUCTION}

Extrapyramidal symptoms (EPS) are a serious adverse effect caused by excessive antagonism of D2 receptor of antipsychotics in the substantia nigra and striatum areas. EPS have great impact on the drug efficacy, drug compliance and social ability of patients with schizophrenia. ${ }^{1}$ Despite the lower incidence of EPS associated with the widespread of the usage of second generation antipsychotics (SGAs), EPS remain a clinically significant issue as its incidence rate remains substantial.

The risk factors for EPS are complicated and related to a lot of factors including demographics, antipsychotics use, and so forth. Previous studies have shown that gender (female), age (elder), high D2 receptor antagonism effect of antipsychotics, usage of first-generation antipsychotics, polytherapy of antipsychotics, longer duration of drug treatment, illness such as brain atrophy, diabetes and substance addiction, and genetic diversity are related to higher incidence of EPS. ${ }^{2}$ However, most of the research uses samples from foreign populations, and therefore the exploration of risk factors of EPS in Chinese patients with schizophrenia is warranted.

The relationships between symptoms of schizophrenia and EPS are complicated and remain to be explored. The study has shown that patients with schizophrenia with EPS often have more severe psychiatric symptoms 
(positive symptoms, negative symptoms, general psychopathology symptoms) and mood symptoms. These psychiatric symptoms along with mood symptoms are positively correlated with EPS symptoms. ${ }^{45}$ The outcomes of previous research indicate that patients with EPS may have worse treatment outcomes compared with those without EPS, which highlights the necessity of early detection of EPS. Whether this phenomenon exists in Chinese patients with schizophrenia remains unknown.

The aim of this study is to explore the risk factors of antipsychotic-induced EPS and their correlation with psychiatric symptoms and mood symptoms of Chinese patients with schizophrenia in the real world. We hypothesised that some demographical and drug-related risk factors of EPS will be found in this study, and the correlation between EPS and symptoms of schizophrenia exists in Chinese patients.

\section{METHODS}

\section{Inclusion criteria}

The sample was derived from a real-world multicentre clinical trial, called the Multi-center Real World Clinical Study of Long-term Outcomes for Schizophrenia by Atypical Antipsychotic Treatment (in China). All enrolled patients were adult patients with schizophrenia who had been admitted to seven psychiatric hospitals or general hospitals from 2011 to 2016. All patients must have met the following inclusion criteria: (1) patients who have been diagnosed with schizophrenia by two psychiatrists independently based on the Diagnostic and Statistical Manual of Mental Disorders-Fourth Edition or the International Classification of Diseases-10th Edition; (2) 18 years old or above; and (3) patients who had taken or intended to take one of the eight atypical antipsychotics allowed by this study (quetiapine/olanzapine/risperidone/aripiprazole/ziprasidone/paliperidone/amisulpride/clozapine). Patients who were participating in other clinical studies and who were considered unfit for this study were excluded. A total of 1027 subjects were enrolled in baseline data. A total of 348 cases were excluded due to the lack of demographic data (gender, age, and so on), EPS ratings and symptoms ratings. Finally, a total of 679 subjects were included in the analysis (figure 1). All patients and their guardians have signed a written informed consent form, and all the assessments were made by trained psychiatrists who have underwent scale consistency training before the first patients were enrolled.

\section{Diagnostic criteria for EPS}

EPS is mainly divided into three types: drug-induced parkinsonism, akathisia and tardive dyskinesia. Patients were considered to have met criteria for drug-induced parkinsonism if they scored 1 (mild) on at least two of the

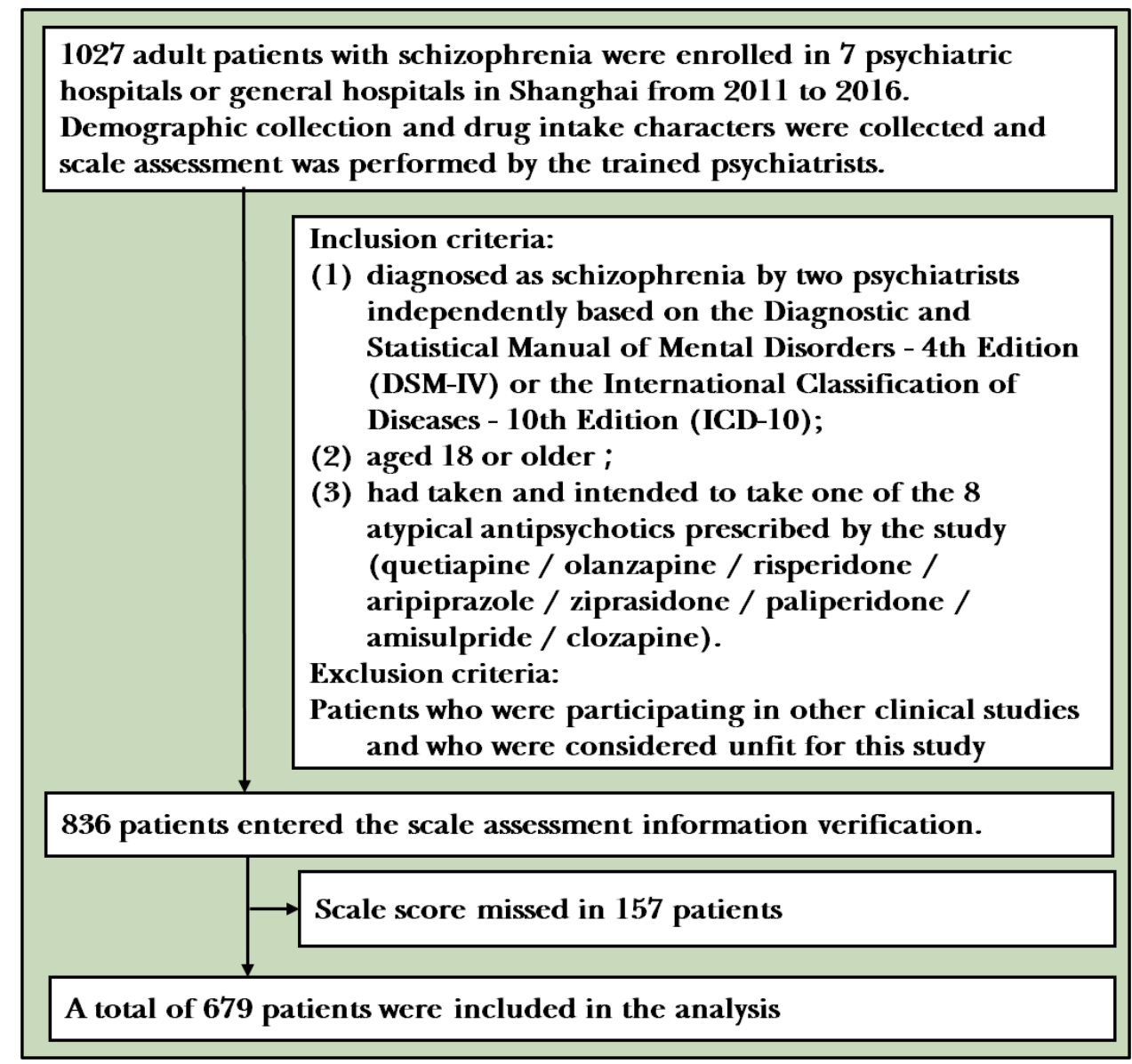

Figure 1 Flowchart of the study. 
six Simpson-Angus Scale (SAS) items or 2 (moderate) on one of the items. Patients were considered to have met criteria for akathisia if they scored at least 2 (mild) on the Barnes Akathisia Rating Scale (BARS) global item. When they scored 2 (mild) on at least two Abnormal Involuntary Movement Scale (AIMS) items or 3 (moderate) on one AIMS item, they were diagnosed with suspected tarive dyskesia (TD) (the diagnosis of TD requires more than two consecutive AIMS assessments). ${ }^{6-8}$ Since anticholinergic drugs could relieve or mask EPS symptoms, all patients who took diphenhydramine hydrochloride were assigned to the EPS group.

\section{Research methods}

This study aims to explore the risk factors of EPS in the real world by comparing demographic data and the drug intake character between the EPS group and the non-EPS group. The demographic data included in the analysis were age, gender, age of onset, duration since first prescribed antipsychotics and illness duration. Drug intake characters include D2 receptor antagonistic effects, atypical antipsychotic drugs monotherapy, atypical antipsychotic drugs polytherapy, typical antipsychotics and atypical antipsychotics polytherapy, combined treatments with mood stabilisers and antidepressants. Antipsychotics are divided into high D2 receptor antagonistic ability, medium D2 receptor antagonistic and low D2 receptor antagonistic ability depending on the classification of recent study and textbook. ${ }^{19}$ High D2 receptor antagonistic antipsychotics which have been used in this study include risperidone, paliperidone, ziprasidone, haloperidol and fluphenazine. Low D2 receptor antagonistic antipsychotics include quetiapine, clozapine, chlorpromazine and sulpiride. Medium D2 receptor antagonistic antipsychotics include olanzapine, amisulpride and perphenazine. Aripiprazole has a high affinity for D2 receptor, but considering the facts that aripiprazole may have both partial agonistic effects and partial antagonistic effects on D2 receptor, aripiprazole is considered as a medium antagonistic antipsychotic drug in this study. ${ }^{10} 11$ The classification of drugs is shown in table 1A,B.

In this study, the correlation between the psychiatric rating and the EPS score was analysed, and the difference of symptoms between the EPS group and the non-EPS group was compared with the correction of the covariant (the risk factors of EPS) which aims to verify the relationship between EPS and the symptoms of schizophrenia. The severity of EPS symptoms was assessed by the total score of 6-item SAS, the BARS global item and the AIMS 7 items total score. ${ }^{6-8}$ The severity of psychiatric symptoms was assessed by the Positive and Negative Symptoms Scale (PANSS). Mood symptoms in patients with schizophrenia were assessed by the Calgary Depression Scale for Schizophrenia (CDSS). The CDSS scale is a nine-item scale specifically designed to assess depressive symptoms in patients with schizophrenia. Each item had four grades $(0=$ without, $1=$ mild, $2=$ moderate, $3=$ severe $)$, and the reliability and validity of the assessment were reliable. ${ }^{12}$
Table 1A The usage of high D2 receptor antagonistic effect antipsychotics

\begin{tabular}{lll}
\hline Antipsychotics & $\begin{array}{l}\text { EPS } \\
\text { group }\end{array}$ & $\begin{array}{l}\text { Non-EPS } \\
\text { group }\end{array}$ \\
\hline Risperidone monotherapy & 40 & 70 \\
Paliperidone monotherapy & 8 & 42 \\
Ziprasidone monotherapy & 3 & 6 \\
$\begin{array}{l}\text { High D2 receptor antagonistic effect } \\
\text { antipsychotics polytherapy }\end{array}$ & 44 & 68 \\
\hline
\end{tabular}

Table 1B The usage of low D2 receptor antagonistic effect antipsychotics

\begin{tabular}{lcl}
\hline Antipsychotics & $\begin{array}{l}\text { EPS } \\
\text { group }\end{array}$ & $\begin{array}{l}\text { Non-EPS } \\
\text { group }\end{array}$ \\
\hline Clozapine monotherapy & 13 & 36 \\
Quetiapine monotherapy & 9 & 16 \\
Olanzapine monotherapy & 25 & 87 \\
Amisulpride monotherapy & 4 & 12 \\
Aripiprazole monotherapy & 12 & 44 \\
Low D2 receptor antagonistic effect & 46 & 94 \\
antipsychotics polytherapy & & \\
\hline
\end{tabular}

EPS, extrapyramidal symptoms.

\section{Statistical methods}

Analysis was performed using SPSS V.23.0 software. Measurement data were expressed as mean (SD). The data which met normal distribution were analysed with t-test. Count data, which were analysed using $\chi^{2}$ tests, were represented with percentage (\%). Mann-Whitney $\mathrm{U}$ test was used to compare non-normal distribution data. Two-sided tests were employed in all statistical tests, $p \leq 0.05$ indicates statistically significant differences. Logistic regression was used to screen out the risk factors of EPS. Correlation between EPS symptoms and psychiatric symptoms was performed using Spearman correlation analysis. Covariance analysis was used to compare the psychiatric symptoms of the EPS group and the non-EPS group with the adjustment of the risk factors of EPS.

\section{RESULTS}

\section{Comparison of demographics and clinical data}

A total of 679 patients with schizophrenia were included in the study, including 204 patients in the EPS group and 475 patients in the non-EPS group. Among them, 126 cases $(18.41 \%)$ had drug-induced parkinsonism, 33 cases $(4.8 \%)$ had akathisia and 23 cases $(3.3 \%)$ had suspected TD. Twenty-two patients took trihexyphenidyl which did not meet the diagnostic criteria for EPS were also included in the EPS group. The mean age of the patients in the EPS group was older than the non-EPS group (40.8 (16.8) vs $37.3(14.0), p=0.01, \mathrm{t}=-2.61)$. The EPS group patients also had longer duration since first prescribed antipsychotics (14.4 (15.2) vs 10.6 (12.0), $p=0.002, \mathrm{Z}=3.1$ ) and longer illness duration (15.8 (15.2) vs 11.7 (12.1), 
Table 2 Comparison of demographic data between EPS group and non-EPS group

\begin{tabular}{|c|c|c|c|c|}
\hline Demographic data & $\begin{array}{l}\text { EPS group } \\
(n=204)\end{array}$ & $\begin{array}{l}\text { Non-EPS group } \\
(\mathrm{n}=475)\end{array}$ & Statistics & $\begin{array}{l}\text { Significant (P } \\
\text { values) }\end{array}$ \\
\hline Age & $40.8(16.8)$ & $37.3(14.0)$ & $t=-2.61$ & $0.01^{\star \star}$ \\
\hline Age of onset & $25.1(9.3)$ & $25.5(9.0)$ & $\mathrm{t}=0.76$ & 0.446 \\
\hline Illness duration & $15.8(12.1)$ & $11.7(12.1)$ & $Z=3.41$ & $0.001^{\star \star \star}$ \\
\hline $\begin{array}{l}\text { Low and medium D2 receptor antagonistic effect } \\
\text { antipsychotics }\end{array}$ & $109(53.4 \%)$ & $290(61.1 \%)$ & & \\
\hline Atypical antipsychotics monotherapy & $114(55.9 \%)$ & $313(65.9 \%)$ & & \\
\hline Atypical antipsychotics polytherapy & $72(35.3 \%)$ & $141(29.7 \%)$ & $X^{2}=8.52$ & $0.014^{*}$ \\
\hline Antidepressants & $12(5.9 \%)$ & $24(5.1 \%)$ & $X^{2}=0.196$ & 0.658 \\
\hline
\end{tabular}

${ }^{*} p \leq 0.0 ;{ }^{* *} p \leq 0.001 ;{ }^{* * *} p \leq 0.0$.

EPS, extrapyramidal symptoms.

$p=0.001, \mathrm{Z}=3.41$ ). There was no statistical difference in the age of onset, and there was a certain trend of difference in gender distribution $\left(\mathrm{X}^{2}=3.716, p=0.054\right)$. The study also found that the rate of those who were taking high D2 receptor antagonistic effect antipsychotics in the EPS group was higher than that in the non-EPS group (44.6\% vs $38.9 \%)$, and the difference was a certain trend $\left(\mathrm{X}^{2}=3.42, p=0.064\right)$. The rate of typical antipsychotics and atypical antipsychotics polytherapy and atypical antipsychotics polytherapy was significantly higher in the EPS group than in the non-EPS group $\left(\mathrm{X}^{2}=8.52, p=0.014\right)$. The drug characters which the patients were taking are shown in table 1. Furthermore, the EPS group had a higher rate of mood stabilisers combination treatment $\left(8.8 \%\right.$ vs $\left.4.6 \%, \mathrm{X}^{2}=4.52, p=0.033\right)$. There was no significant difference in the combination of antidepressants between the two groups. The results are shown in table 2 .

The data which met normal distribution were analysed with t-test. Count data were represented with percentage (\%) which were analysed with $\chi^{2}$ tests. Mann-Whitney U test was used to compare non-normal distribution data.

\section{Factors of EPS}

In this study, variables whether having statistically significant difference or not in the demographic data and drug intake factors were included in the regression analysis to analyse the risk factors of EPS. There were nine variables included: gender, age, duration since first antipsychotics prescription, age of onset, illness duration, D2 receptor antagonistic ability, atypical antipsychotics monotherapy, atypical antipsychotics polytherapy, typical and atypical antipsychotics, and combined treatment with mood stabilisers. Logistic regression analysis showed that the two variables showed statistical difference.Antipsychotics with high antagonistic ability and the illness duration were risk factors for EPS. The risk factors of EPS are shown in table 3 .

\section{Correlation between EPS scale score and symptoms of schizophrenia}

Spearman correlation was used to analyse the correlation between EPS severity (SAS, BARS, AIMS score) and symptoms of schizophrenia (PANSS, CDSS score) in 679 patients. SAS total score was positively correlated with PANSS negative total score $(\mathrm{R}=0.20, p<0.001)$, PANSS general psychopathology total score $(\mathrm{R}=0.12, p=0.002)$ and PANSS total score $(\mathrm{R}=0.13, p=0.001)$. BARS global score was positively correlated with PANSS positive total score $(\mathrm{R}=0.048, p=0.08)$, PANSS general psychopathology total score $(p \leq 0.001, \mathrm{R}=0.13)$, PANSS total score $(\mathrm{R}=0.11$, $p=0.005)$ and CDSS total score $(\mathrm{R}=0.26, p<0.001)$. AIMS total score was positively correlated with the total score of PANSS negative scale $(\mathrm{R}=0.09, p=0.018)$. The correlation between EPS and symptoms of schizophrenia is shown in table 4 .

\section{Comparison of symptoms between EPS group and non-EPS group}

After adjusting for covariates including age, duration since first prescribed antipsychotics and illness duration, the EPS group had higher scores of the PANSS negative total score (17.4 (7.4) vs 20.8 (7.9), $F=21.75, p<0.001)$, PANSS general psychopathological total score (32.3 (10.7) vs 35.3 (10.3), $F=13.67, p=0.001$ ), PANSS total score (65.7 (21.2) vs 71.7 (20.1), $F=13.671, p=0.001)$ and CDSS total score $(2.3(3.7)$ vs $2(3.8), F=5.953, p=0.015)$ than the non-EPS group, and there was no significant difference in the scores of the positive scales between the two groups. The results are shown in table 5 . 
Table 3 Analysis of risk factors of EPS

\begin{tabular}{lcccccc}
\hline Factors & B & SE & Wald & P values & OR & 95\% Cl \\
\hline Age & 0.03 & 0.02 & 1.92 & 0.166 & 1.03 & 0.99 to 1.08 \\
Gender & -0.24 & 0.17 & 1.92 & 0.166 & 0.79 & 0.56 to 1.11 \\
Age of onset & -0.03 & 0.02 & 1.33 & 0.248 & 0.97 & 0.93 to 1.02 \\
$\begin{array}{l}\text { Typical and atypical antipsychotics } \\
\text { polytherapy }\end{array}$ & 0.59 & 0.36 & 2.68 & 0.101 & 1.80 & 0.89 to 3.66 \\
$\begin{array}{l}\text { Atypical antipsychotics polytherapy } \\
\text { Taking antipsychotics with high D2 }\end{array}$ & 0.24 & 0.19 & 1.64 & 0.201 & 1.27 & 0.88 to 1.84 \\
$\begin{array}{l}\text { antagonistic ability } \\
\text { Illness duration }\end{array}$ & 0.37 & 0.17 & 4.59 & $0.032^{*}$ & 1.44 & 1.03 to 2.02 \\
Duration since first prescribed antipsychotics & 0.02 & 0.01 & 14.49 & $0.001^{* *}$ & 1.02 & 1.01 to 1.04 \\
Combined treatments of mood stabiliser & 0.52 & 0.02 & 0.96 & 0.328 & 1.02 & 0.98 to 1.06 \\
Constant & -1.326 & 0.149 & 78.84 & $<0.001$ & 0.27 & \\
\hline
\end{tabular}

${ }^{*} p \leq 0.05 ;{ }^{* *} p \leq 0.01$.

EPS, extrapyramidal symptoms.

\section{DISCUSSION}

\section{Main findings}

Based on the demographic data and drug intake character, this study found that patients in the EPS group were older combined with a longer duration of illness and drug treatment. More typical and atypical antipsychotics polytherapy, atypical antipsychotics polytherapy and mood stabilisers combined treatment can be found in the EPS group. There was a trend difference in gender and antipsychotic D2 receptor antagonism in the EPS group. When variables with statistical and trend differences were included in the logistic regression analysis, the study found that antipsychotics with high D2 receptor antagonism and illness duration were risk factors of EPS, and the relationship between gender, age, monotherapy or

Table 4 Correlation between EPS scale score and symptoms of schizophrenia with Spearman correlation analysis

\begin{tabular}{|c|c|c|c|}
\hline Item & $\begin{array}{l}\text { SAS total } \\
\text { score }\end{array}$ & $\begin{array}{l}\text { BARS global } \\
\text { score }\end{array}$ & $\begin{array}{l}\text { AlMS total } \\
\text { score }\end{array}$ \\
\hline $\begin{array}{l}\text { PANSS positive total } \\
\text { score }\end{array}$ & $\begin{array}{l}R=-0.02 \\
p=0.375\end{array}$ & $\begin{array}{l}R=0.08 \\
p=0.048^{\star}\end{array}$ & $\begin{array}{l}R=-0.01 \\
p=0.759\end{array}$ \\
\hline $\begin{array}{l}\text { PANSS negative } \\
\text { total score }\end{array}$ & $\begin{array}{l}\mathrm{R}=0.20 \\
p<0.001^{\star \star}\end{array}$ & $\begin{array}{l}\mathrm{R}=0.05 \\
p=0.225\end{array}$ & $\begin{array}{l}\mathrm{R}=0.09 \\
p=0.018^{*}\end{array}$ \\
\hline $\begin{array}{l}\text { PANSS general } \\
\text { psychopathological } \\
\text { total score }\end{array}$ & $\begin{array}{l}R=0.12 \\
p=0.002^{\star \star *}\end{array}$ & $\begin{array}{l}R=0.13 \\
p=0.001^{* *}\end{array}$ & $\begin{array}{l}\mathrm{R}=0.07 \\
p=0.054\end{array}$ \\
\hline PANSS total score & $\begin{array}{l}R=0.13 \\
p=0.001^{\star *}\end{array}$ & $\begin{array}{l}R=0.11 \\
p=0.005^{\star \star \star}\end{array}$ & $\begin{array}{l}\mathrm{R}=0.10 \\
p=0.072\end{array}$ \\
\hline CDSS total score & $\begin{array}{l}R=0.07 \\
p=0.074\end{array}$ & $\begin{array}{l}\mathrm{R}=0.26 \\
p<0.001^{* *}\end{array}$ & $\begin{array}{l}R=0.03 \\
p=0.483\end{array}$ \\
\hline
\end{tabular}

${ }^{*} p \leq 0.05 ;{ }^{* *} p \leq 0.01 ;{ }^{* * *} p \leq 0.001$

AIMS, Abnormal Involuntary Movement Scale; BARS, Barnes Akathisia Rating Scale; CDSS, Calgary Depression Scale for Schizophrenia; EPS, extrapyramidal symptoms; PANSS, Positive and Negative Symptoms Scale; SAS, Simpson-Angus Scale. polytherapy of antipsychotics (no matter if it is typical or atypical antipsychotics) and EPS did not reach statistical difference. The relative high incidence of EPS in patients taking typical antipsychotics was consistent with the results of some clinical studies. ${ }^{13-15}$ However, in recent years, some high-grade clinical trials with large sample including Clinical Antipsychotic Trials of InterventionEffectiveness (CATIE)、 The Cost Utility of the Latest Antipsychotics in SchizophreniaStudy Band 1 (CUTLASS) and systematic reviews failed to reach the same conclusion. ${ }^{6} 1617$ These studies demonstrated that atypical antipsychotic drugs might not have a significant advantage in reducing the incidence of EPS. Hugenholtz and colleauges' study showed that some randomised controlled trials demonstrated the conclusion that atypical antipsychotic drugs caused less EPS because the dose of typical antipsychotics group was usually higher than the recommended dose while not combined with anticholinergics. ${ }^{18}$ A systematic review of 31 clinical studies (2320 samples) by Leucht and colleagues found that only clozapine in the second-generation antipsychotics had less EPS than typical low D2 receptor antagonistic typical antipsychotics. ${ }^{19}$ There was no statistically significant difference in the incidence of EPS between other atypical antipsychotics (such as risperidone, ziprasidone, and so on) and typical antipsychotic drugs with low D2 receptor antagonism. The outcomes of study in Chinese populations also indicate that those who are taking high D2 receptor antagonistic effect atypical antipsychotic risperidone induce more EPS than those with low and moderate $\mathrm{D} 2$ receptor antagonistic effect. ${ }^{2021}$ In summary, the $\mathrm{D} 2$ receptor antagonism effect of antipsychotic drugs may be related to the occurrence of EPS, and the impact of monotherapy or polytherapy of antipsychotics and classification of atypical or typical antipsychotics on incidence of EPS needs to be verified by larger sample trials.

The study also found that illness duration rather than duration since first prescribed antipsychotics was a risk 


\begin{tabular}{|c|c|c|c|c|}
\hline & $\begin{array}{l}\text { EPS group } \\
(n=204)\end{array}$ & $\begin{array}{l}\text { Non-EPS group } \\
(n=475)\end{array}$ & Statistics $(\boldsymbol{F})$ & $\begin{array}{l}\text { Significant (P } \\
\text { values) }\end{array}$ \\
\hline PANSS positive scale total score & $15.9(7.2)$ & $15.6(6.5)$ & 0.04 & 0.837 \\
\hline PANSS negative scale total score & $17.4(7.4)$ & $20.8(7.9)$ & 21.75 & $0.001^{*}$ \\
\hline PANSS general psychopathological scale total score & $32.3(10.7)$ & $35.2(10.3)$ & 13.67 & $0.001^{\star \star}$ \\
\hline PANSS total score & $65.7(21.2)$ & $71.7(20.1)$ & 11.94 & $0.001^{\star *}$ \\
\hline CDSS total score & $2.3(3.7)$ & $2.9(3.8)$ & 5.953 & $0.015^{\star \star}$ \\
\hline
\end{tabular}

${ }^{*} p<0.05 ;{ }^{* *} p<0.01$.

CDSS, Calgary Depression Scale for Schizophrenia; EPS, extrapyramidal symptoms; PANSS, Positive and Negative Symptoms Scale.

factor of EPS. This result was consistent with Go's findings on tardive dyskesia. ${ }^{22}$ This conclusion demonstrates that the incidence of EPS may be related to the character of antipsychotics and to the illness itself. Docx and colleagues suggested EPS, catatonia, mental retardation and neurological soft signs (psychomotor syndrome) are parts of the phenotype of schizophrenia. ${ }^{23}$ The pathogenesis of psychomotor syndrome may be related to neurodevelopmental disorder or the dysfunction of the basal ganglia in patients with schizophrenia, and these dysfunctions are closely related to the pathogenesis of schizophrenia itself. ${ }^{24}{ }^{25}$ Some clinical studies have also found that patients who are drug-naïve first-episode schizophrenic may also have EPS symptoms such as drug-induced parkinsonism and tardive dyskesia. ${ }^{24}{ }^{26}$ The relationship between the character of schizophrenia (such as symptoms severity and illness duration) and the occurrence of EPS still needs to be further verified and explored.

This study found that severity of different types of EPS was significantly correlated with the severity of schizophrenia symptoms. The severity of drug-induced parkinsonism (SAS score) was significantly correlated with the PANSS negative total score, PANSS general psychopathological total score and PANSS total score. All the differences were statistically significant. Rybakowski and colleagues and Mentzel and colleagues also found a correlation between drug-induced parkinsonism and PANSS general psychopathological symptom scores. ${ }^{2425}$ The severity of akathisia (BARS global subscale score) was significantly correlated with the PANSS general psychopathological total score, PANSS total score and CDSS total score. Baynes and colleagues, Gebhardt and collagues and Majadas and colleagues validated the relationship between the severity of schizophrenia, depressive symptoms and akathisia. ${ }^{26-28}$ So far, no clinical studies have shown that the severity of akathisia is correlated with the positive symptoms. Considering the small correlation coefficient $(r<0.1)$ of this relationship, the correlation between the severity of drug-induced akathisia and the PANSS positive score might be a coincidence. The severity of tardive dyskinesia (first seven items of total scores of the AIMS scale) was significantly correlated with PANSS negative total scale. Mentzel and colleagues and Gebhardt and colleagues validated the relationship between tardive dyskinesia and negative symptoms of schizophrenia. ${ }^{25} 26$ The results of the research suggested that different types of EPS are positively correlated with the severity of psychiatric and mood symptoms in schizophrenia.

The correlation between EPS symptoms and schizophrenic symptoms was further validated by comparing the scores of PANSS subscale and CDSS in EPS and non-EPS groups with the adjustment of the covariates. The study found that the PANSS negative total score, the general psychopathology scale score, the PANSS total score and the CDSS total score in the EPS group were significantly higher than those in the non-EPS group. This result indicated that schizophrenia with EPS had more severe psychiatric symptoms and mood symptoms than those without EPS. There was no significant difference in positive symptoms. The studies by Huang and colleagues, Baynes and colleagues and Gebhardt and colleagues also validated this result. ${ }^{262729}$

The correlation between EPS and psychiatric symptoms and mood symptoms of Chinese patients with schizophrenia is validated in this study. The mechanisms of this phenomenon are complicated and remain unclear. First, both EPS and schizophrenia can induce psychiatric symptoms and mood symptoms. The secondary negative symptoms which are induced by EPS and the negative symptoms of schizophrenia are very alike and difficult to distinguish, and the depressive symptoms in patients of schizophrenia are induced by a lot of factors, and EPS is one of the factors which deteriorate the mood symptoms due to the great pain induced by EPS, such as acute dystonia and inner restlessness. The secondary negative symptoms and pain induced by EPS can deteriorate the psychiatric symptoms and mood symptoms of schizophrenia which lead to the increase of PANSS and CDSS ratings. On the other hand, the increased dosage of antipsychotics caused by the more severe symptoms of schizophrenia which lead to higher induction of EPS also makes sense. Last but not least, schizophrenia is a neuropsychiatric disorder, EPS accompanied with other psychomotor symptoms may be the phenotype of schizophrenia as mentioned above. ${ }^{23}$ Therefore, more severe EPS and more severe psychiatric symptoms may be all due to more severe illness itself. In summary, the mechanism of the correlation of EPS and psychiatric symptoms 
accompanied with mood symptoms of schizophrenia does exist in Chinese patients with schizophrenia, but whether EPS is the factor of the symptoms of schizophrenia or vice versa remains to be explored.

\section{Limitations}

This study is based on cross-sectional data in real-world research, so it is impossible to demonstrate a trend and correlation between the changes of psychiatric symptoms of schizophrenia and the severity of EPS in longterm research. Future studies can concentrate on the long-term alternation of EPS severity and psychiatric and mood symptoms of schizophrenia which can further reveal the relationship between EPS and schizophrenia. In thist study, those who didn't fit in the dignositic criteria for EPS but were currently taking anticholinergics are included in EPS group. This may result in the inclusion of someone who without EPS considering the fact that some anticholinergics are given in advance to avoid risk of developing EPS especially when they are taking first generation antipsychotics (FGAs), which lead to a bias to the results. The risk factors of EPS may not be comprehensive in this study. Future research could investigate whether factors such as drug dose, blood drug concentration and substance dependence have an impact on the occurrence of EPS in Chinese patients with schizophrenia.

\section{Implications}

In summary, this study has found that taking high D2 receptor antagonistic effect antipsychotics and illness duration of schizophrenia may be risk factors of EPS. The impact of polytherapy or monotherapy and classification of antipsychotics on the occurrence of EPS remains to be further explored. The psychiatric and mood symptoms of schizophrenia were positively correlated with the severity of diverse types of EPS, and psychiatric and mood symptoms were more severe in the EPS group compared with the non-EPS group. The occurrence of EPS was related to poor treatment outcomes and poor prognosis in Chinese patients with schizophrenia.

Contributors WJ and YZ are responsible for the statistical analysis and the writing of the paper. HL is responsible for the scientific design of this study. YS and WY are responsible for the data checking and literature evaluation of this paper.

Funding Multicentre clinical study of Shanghai Jiao Tong University School of Medicine (DLY201620, 2016-2018): Real-world, multicentre clinical study of the long-term outcome of atypical antipsychotics in the treatment of schizophrenia 'Major new drug creation' Major science and technology project, National Major Project for IND, $2018 Z X 09734005$ (2018-2020), Translational Medicine Collaborative Innovation Collaborative Research Project-Shanghai Mental Health Center Sub-center Construction (New Drug Clinical Trial Conversion Platform) (TM201624 , 2016-2018), Shanghai Science and Technology Commission Research Project (17411970300).

Competing interests None declared.

Patient consent for publication Obtained.

Ethics approval The Shanghai Mental Health Center Ethics Committee approved this study.

Provenance and peer review Not commissioned; externally peer reviewed.

Data sharing statement No additional data are available.
Open access This is an open access article distributed in accordance with the Creative Commons Attribution Non Commercial (CC BY-NC 4.0) license, which permits others to distribute, remix, adapt, build upon this work non-commercially, and license their derivative works on different terms, provided the original work is properly cited and the use is non-commercial. See: http://creativecommons.org/ licenses/by-nc/4.0

\section{REFERENCES}

1. Divac N, Prostran M, Jakovcevski I, et al. Second-generation antipsychotics and extrapyramidal adverse effects. Biomed Res Int 2014;2014:1-6.

2. Mehta SH, Morgan JC, Sethi KD. Drug-induced movement disorders. Neurol Clin 2015;33:153-74.

3. Miller DD, McEvoy JP, Davis SM, et al. Clinical correlates of tardive dyskinesia in schizophrenia: baseline data from the CATIE schizophrenia trial. Schizophr Res 2005;80:33-43.

4. Pappa S, Dazzan P. Spontaneous movement disorders in antipsychotic-naive patients with first-episode psychoses: a systematic review. Psychol Med 2009;39:1065-76.

5. Abboud R, Noronha C, Diwadkar VA. Motor system dysfunction in the schizophrenia diathesis: neural systems to neurotransmitters. Eur Psychiatry 2017;44:125-33.

6. Miller DD, Caroff SN, Davis SM, et al. Extrapyramidal sideeffects of antipsychotics in a randomised trial. Br J Psychiatry 2008;193:279-88.

7. Schooler NR, Kane JM. Research diagnoses for tardive dyskinesia. Arch Gen Psychiatry 1982;39:486-7.

8. Simpson GM, B. M, B. GH, et al. A rating scale for extrapyramidal side effects. Acta Psychiatr Scand 1970;45:11-19.

9. Wang CY. Somatic therapy. In: Jiang KD, Hao W, Yu X, eds. Psychiatry. 7ty edition. Beijing: People's Health Publishing House, 2014: 226-46.

10. Etminan M, Procyshyn RM, Samii A, et al. Risk of extrapyramidal adverse events with aripiprazole. J Clin Psychopharmacol 2016;36:472-4.

11. Brust TF, Hayes MP, Roman DL, et al. New functional activity of aripiprazole revealed: robust antagonism of D2 dopamine receptor-

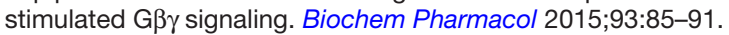

12. Addington $\mathrm{D}$, Addington J, Maticka-Tyndale $\mathrm{E}$, et al. Reliability and validity of a depression rating scale for schizophrenics. Schizophr Res 1992;6:201-8.

13. Lee $\mathrm{C}, \mathrm{Wu} \mathrm{KH}, \mathrm{Habil} \mathrm{H}$, et al. Treatment with olanzapine, risperidone or typical antipsychotic drugs in Asian patients with schizophrenia. Aust N Z J Psychiatry 2006;40:437-45.

14. Savica R, Grossardt BR, Bower JH, et al. Incidence and time trends of drug-induced parkinsonism: a 30-year population-based study. Mov Disord. 2017;32:227-34.

15. Girgis RR, Phillips MR, Li X, et al. Clozapine V. chlorpromazine in treatment-naive, first-episode schizophrenia: 9-year outcomes of a randomised clinical trial. Br J Psychiatry 2011;199:281-8.

16. Peluso MJ, Lewis SW, Barnes TR, et al. Extrapyramidal motor sideeffects of first- and second-generation antipsychotic drugs. $\mathrm{Br} \mathrm{J}$ Psychiatry 2012;200:387-92.

17. Geddes J, Freemantle N, Harrison P, et al. Atypical antipsychotics in the treatment of schizophrenia: systematic overview and metaregression analysis. BMJ 2000;321:1371-6.

18. Hugenholtz GW, Heerdink ER, Stolker JJ, et al. Haloperidol dose when used as active comparator in randomized controlled trials with atypical antipsychotics in schizophrenia: comparison with officially recommended doses. J Clin Psychiatry 2006;67:897-903.

19. Leucht S, Wahlbeck K, Hamann J, et al. New generation antipsychotics versus low-potency conventional antipsychotics: a systematic review and meta-analysis. The Lancet 2003;361:1581-9.

20. Bai Z, Wang G, Cai S, et al. Efficacy, acceptability and tolerability of 8 atypical antipsychotics in Chinese patients with acute schizophrenia: a network meta-analysis. Schizophr Res 2017;185:73-9.

21. Li Y, Li H, Liu Y, et al. Comparison of quetiapine and risperidone in Chinese Han patients with schizophrenia: results of a single-blind, randomized study. Curr Med Res Opin 2012;28:1725-32.

22. Go CL, Rosales RL, Caraos RJ, et al. The current prevalence and factors associated with tardive dyskinesia among Filipino schizophrenic patients. Parkinsonism Relat Disord 2009;15:655-9.

23. Docx L, Morrens M, Bervoets C, et al. Parsing the components of the psychomotor syndrome in schizophrenia. Acta Psychiatr Scand 2012;126:256-65.

24. Rybakowski JK, Vansteelandt K, Remlinger-Molenda A, et al. Extrapyramidal symptoms during treatment of first schizophrenia 
episode: results from EUFEST. Eur Neuropsychopharmacol 2014;24:1500-5.

25. Mentzel TQ, Lieverse R, Bloemen O, et al. High incidence and prevalence of drug-related movement disorders in young patients with psychotic disorders. J Clin Psychopharmacol 2017;37:231-8.

26. Gebhardt S, Härtling F, Hanke M, et al. Relations between movement disorders and psychopathology under predominantly atypical antipsychotic treatment in adolescent patients with schizophrenia. Eur Child Adolesc Psychiatry 2008;17:44-53.
27. Baynes D, Mulholland C, Cooper SJ, et al. Depressive symptoms in stable chronic schizophrenia: prevalence and relationship to psychopathology and treatment. Schizophr Res 2000;45:47-56.

28. Majadas S, Olivares J, Galan J, et al. Prevalence of depression and its relationship with other clinical characteristics in a sample of patients with stable schizophrenia. Compr Psychiatry 2012;53:145-51.

29. Huang Y, Pan L, Teng F, et al. A cross-sectional study on the characteristics of tardive dyskinesia in patients with chronic schizophrenia. Shanghai Arch Psychiatry 2017;29:295-303.

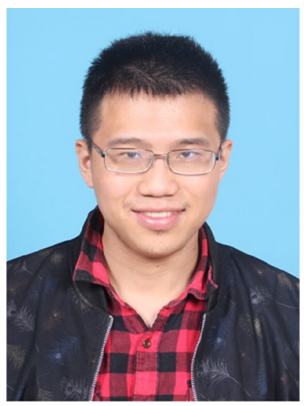

Jiajun Weng graduated from China Medical University in 2016, and he is currently a postgraduate student of Shanghai Jiao Tong University of medicine in Shanghai Mental Health center. His research interest includes neurological side effects of schizophrenia patients. 